\title{
Extended finite-element method for modeling the mechanical behavior of functionally graded material plates with multiple random inclusions
}

\author{
Kim Bang Tran, The Huy Tran, Quoc Tinh Bui and Tich Thien Truong
}

\begin{abstract}
Functionally graded material is of great importance in many engineering problems. Here the effect of multiple random inclusions in functionally graded material (FGM) is investigated in this paper. Since the geometry of entire model becomes complicated when many inclusions with different sizes appearing in the body, a methodology to model those inclusions without meshing the internal boundaries is proposed. The numerical method couples the level set method to the extended finite-element method (X-FEM). In the X-FEM, the finite-element approximation is enriched by additional functions through the notion of partition of unity. The level set method is used for representing the location of random inclusions. Numerical examples are presented to demonstrate the accuracy and potential of this technique. The obtained results are compared with available refered results and COMSOL, the finite element method software.
\end{abstract}

Index Terms - Extended finite-element method; multiple; random; inclusions, functionally graded material.

Manuscript Received on March 15 ${ }^{\text {th }}$, 2017, Manuscript Revised on November 01 ${ }^{\text {st }}, 2017$.

This research is funded by Ho Chi Minh City University of Technology -VNU-HCM, under grant number T-KHUD2016-69.

Kim Bang Tran, Ho Chi Minh City University of Technology, VNU-HCM, Vietnam (e-mail: tkbang@hcmut.edu.vn).

The Huy Tran, Ho Chi Minh city University of Technology, VNU-HCM, Vietnam. (e-mail: thehuydhbk@gmail.com).

Tinh Quoc Bui, Department of Civil and Environmental Engineering, Tokyo Institute of Technology, Japan (email:tinh.buiquoc@gmail.com).

Tich Thien Truong, Ho Chi Minh city University of Technology, VNU-HCM, Vietnam (e-mail: tttruong@hcmut.edu.vn).

\section{INTRODUCTION}

$\mathrm{H}$ omogeneous materials often find it difficult to meet complex requirements in important technical areas. This problem can be solved by using Functionally Graded Materials (FGM). FGM is a composite material whose mechanical properties change with a mathematical function. This function can contain a variable that is the coordinates of a point on an object. Because the material properties change throughout the body, FGM is of great interest in various technical fields. The main advantage of FGM is that there is no boundary between two different materials and therefore will not lead to discontinuous stress field in the body, despite the fact that the material properties may change drastically. In addition, the FGM can be created to optimize the stress distribution in the material. This is one of the new generation materials. In recent years, FGM has been used in most modern engineering disciplines, such as insulation in gas turbine engines, missile launchers, sensors, nanostructured materials and especially in space industry.

Functionally graded materials were used as alternative materials in some applications. Their special feature makes them very useful in reducing stress concentration but the exist of inclusion may reduce its stiffness. So, modeling the inclusion in FGM play a greatly important role in practice because they may cause the failure.

Most of the problem of discontinuous interfaces such as holes and inclusion is investigated with homogeneous material [1-3], [5] or the FGM structure contains only one defect such as void [4]. When modeling the interface problems by means of the finite element methods, the defect faces must be coincided with the edge of the elements and the FEM has encountered many 
difficulties. To overcome these difficulties, the extended finite element method (XFEM) was developed to solve those problems. In this paper, we present the XFEM for modeling multiple random inclusions in a finite FGM plate with arbitrarily varying elastic properties in the transverse direction. Poisson's ratio is held constant and Young's modulus is considered to vary across the radius and $\mathrm{x}$-axis

\section{EXTENED Finite ELEMENT METHOD FoR MATERIAL DISCONTINUITY PROBLEMS}

When multiple inclusions appear in objects with random sizes and positions, traditional finite element grids need to follow the profile of these particles. In the XFEM, the presence of inclusion does not alter the original element mesh. XFEM allows particle boundaries to cut through the mesh. The behavior of particles will be described by the enrichment function.

\subsection{Level set method for inclusions detection}

In XFEM, the level set method is used to detect discontinuous boundaries. According to [3], a boundary of an inclusion can be considered a material interface.

To calculate the normal level set function $\phi$, consider $\Gamma$ is the geometry of an inclusion. At any point $x$, we define the scattering point $x_{\Gamma}$ on the boundary so that the distance $\left\|x-x_{\Gamma}\right\|$ Is the smallest. The level set function $\phi$ can be expressed as follows

$$
\phi(x)= \pm \min _{x_{\Gamma} \in \Gamma}\left\|x-x_{\Gamma}\right\|
$$

The appearance of inclusion with a particular boundary $\Gamma$ can be detected by the level set value $\phi$ as depicted in Fig. 1. In the whole body, $\phi<0$ at any point located inside the domain bounded by $\Gamma$ and $\phi>0$ at any point located outside the domain.

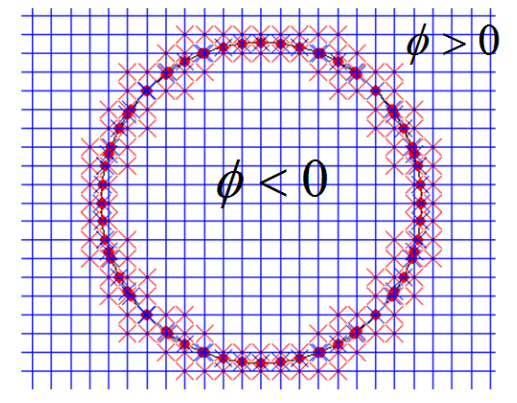

Fig. 1. Signed distance function $\phi$ can be calculated as follows

$\phi=\left\|x-x_{c}\right\|-r_{c}$

With $x_{c}$ and $r_{c}$ is the center and radius of the impurity particle.

\subsection{Enrichment functions for material discontinuities}

To describe the physical properties of a material discontinuities element, we will use the absolute enrichment function as depicted in Fig. 2. According to [3], this function can be defined as the absolute value of the signed distance function as follow

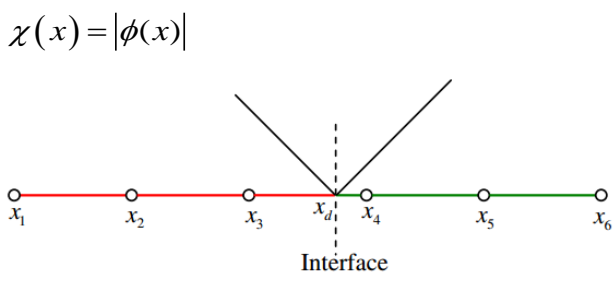

Fig. 2. Jump function

Within a certain element, $\phi(\mathrm{x})$ can be obtained by interpolating the nodal signed distances using the partition of unity as

$\phi(x)=\sum_{I} N_{I} \phi_{I}(x)$

$\chi(x)$ can be calculated by interpolating the nodal signed distances within an element

$\chi(x)=\left|\sum_{I} N_{I}(x) \phi_{I}(x)\right|$

Where $N_{I}$ is shape function at node I

Smoothing of $\chi$ away from the element layer containing the interface yields

$\chi=\chi(x)-\chi\left(x_{I}\right)$

as shown in Fig. 3

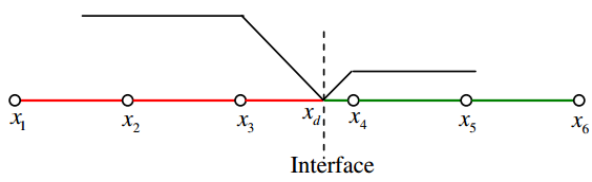

Fig. 3. Jump function after smoothing

After smoothing, the absolute enrichment function takes the form

$$
\chi(x)=\sum_{I} N_{I}(x)\left|\phi_{I}(x)\right|-\left|\sum_{I} N_{I}(x) \phi_{I}(x)\right|
$$

If the particle is in circular form, the value $\phi$ 
The derivative of absolute enrichment function with respect to $\mathrm{x}$ is given as shown in Fig. 4 by

$$
\begin{aligned}
& \chi(x)_{, x}=\sum_{I} \frac{\partial N_{I}(x)}{\partial x}\left|\phi_{I}(x)\right| \\
& -\frac{\sum_{I} N_{I}(x) \phi_{I}(x)}{\left|\sum_{I} N_{I}(x) \phi_{I}(x)\right|} \sum_{I} \frac{\partial N_{I}(x)}{\partial x} \phi_{I}(x) \\
& x_{1}
\end{aligned}
$$

Fig. 4. Jump function after smoothing

\subsection{XFEM for material interface}

According to [3], the displacement field of a two-dimensional element with material discontinuity will be of the following form

$u(\mathbf{x})=\sum_{j=1}^{n} N_{j}(\mathbf{x})[u_{j}+\underbrace{\chi(\mathbf{x}) a_{j}}_{j \in n_{r}}]$

$N$ is the total number of nodes and $n$ is the number of nodes under the element; $u$ is the transposing element at the nodes of the element as in the finite element method, a is the degree of freedom added at the enriched nodes and $\chi(x)$ is the enrichment function to describe the material discontinuity of the material boundary elements passing through.

With the stiffness matrix $\mathrm{K}$ of the enriched elements will be computed according to the formula

$$
\begin{aligned}
K_{i j}^{e} & =\left[\begin{array}{ll}
K_{i j}^{u u} & K_{i j}^{u a} \\
K_{i j}^{a u} & K_{i j}^{a a}
\end{array}\right] \\
K_{i j}^{r s} & =\int_{\Omega^{e}}\left(B_{i}^{r}\right)^{T} \mathbf{D} B_{j}^{s} d \Omega \\
r, s & =u, a
\end{aligned}
$$

$B_{i}^{b}=\left[\begin{array}{cc}\left(N_{i} \chi\right)_{, x} & 0 \\ 0 & \left(N_{i} \chi\right)_{, y} \\ \left(N_{i} \chi\right)_{, y} & \left(N_{i} \chi\right)_{, x}\end{array}\right]$

As the FGM has the properties changing throughout the body, we need to divide the problem domain into a set of elements and obtained the information on node coordinates to take the Gaussian integral. Repeat on each Gauss point: compute the deformation matrix $\mathrm{B}$ at the Gauss point under consideration, compute the material matrix $\mathrm{D}$ at the point Gauss is considering, compute the element's stiffness matrix, assemble the element stiffness matrix into the global stiffness matrix.

\section{NUMERICAL EXAMPLES}

\subsection{Square plate with one circular inclusion}

In the first example, a square plate with a circular inclusion is considered [1]. The model geometry and boundary conditions are described in Fig. 5. The plate side is $\mathrm{L}=5 \mathrm{~m}$ and the external load is $q=100 \mathrm{~N} / \mathrm{m}$. The lower edge of the plate is clamped. The matrix and inclusion materials are taken such as $E_{1}=3.10^{7} \mathrm{~N} / \mathrm{m}^{2}, v_{1}=0.3$ and $E_{2}=$ $3.10^{6} \mathrm{~N} / \mathrm{m}^{2}, \quad v_{2}=0.25$. Plane stress state is investigated. The XFEM mesh and enriched nodes are presented for this example in Fig. 6

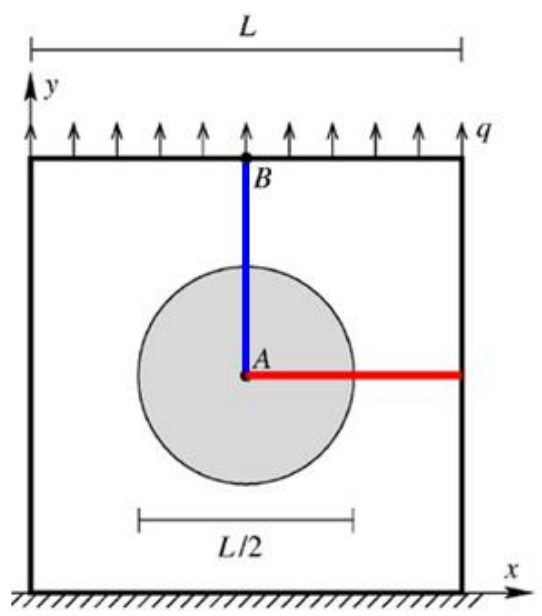

Fig.5. Square plate with one circular inclusion

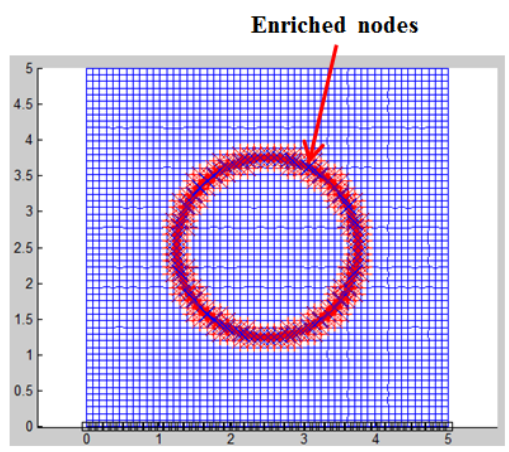

Fig.6. XFEM mesh and enriched nodes

We check the accuracy of the XFEM by comparing the obtained solutions with those given in previous work [1] as depicted in Fig. 7 and Fig. 8. 
The $\mathrm{u}_{\mathrm{x}}$ displacement comparison is performed for the points along the horizontal red solid line of Fig. 5

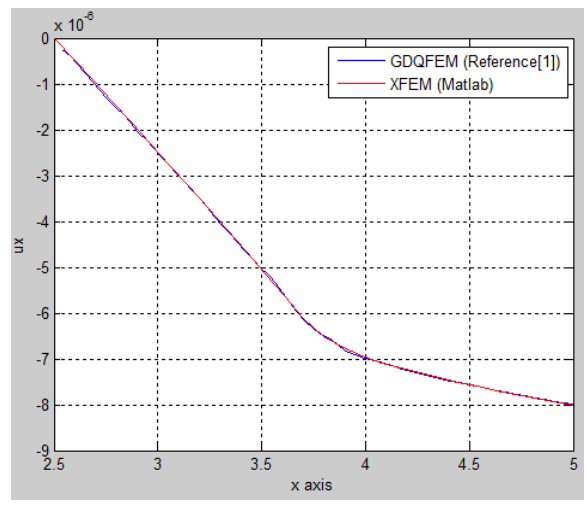

Fig.7. $\mathrm{u}_{\mathrm{x}}$ displacement comparison

The $\mathrm{u}_{\mathrm{y}}$ displacement comparison is performed for the points along vertical blue solid line of Fig.5.

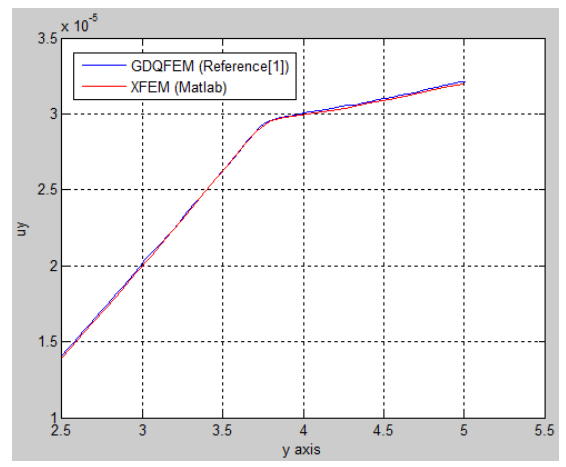

Fig.8. $\mathrm{u}_{\mathrm{y}}$ displacement comparison

We can see that the displacement results obtained by the XFEM matches well with those refered results [1], using GDQFEM.

3.2 FGM plate with material variation in the $x$ direction with seven circular inclusions

In the next example, we consider a rectangular isotropic FGM plate with material variation in the Cartesian $\mathrm{x}$-direction, the dimensions and are depicted in Fig. 9. The external load is $q=1$ $\mathrm{N} / \mathrm{m}^{2}$. The lower edge of the plate is clamped and plane strain state is assumed. The plate contains seven circular inclusions. All inclusions have different radius and different positions as depicted in table 1. The Poisson's ratio of the matrix is assumed to be constant $v=0.3$ and the elastic modulus $\mathrm{E}$ of the matrix varies exponentially from the left to the right edge as follow

$E(x)=E_{0} e^{\beta x}$ where $E_{0}=10^{3} \mathrm{~Pa}$ and $\beta=2$
The Poisson's ratio of the inclusion is assumed to be constant $v=0.35$ and the elastic modulus $\mathrm{E}$ of the matrix varies exponentially from the left to the right edge as follow

\begin{tabular}{cccc}
$E(x)=E_{0} e^{\beta x}$ where $E_{0}=2.10^{3} \mathrm{~Pa}$ and $\beta=2$ \\
TABLE I \\
\hline POSITIONS OF INCLUSION \\
\hline $\begin{array}{c}\text { X-position } \\
(\mathrm{m})\end{array}$ & $\begin{array}{c}\text { Y-position } \\
(\mathrm{m})\end{array}$ & $\begin{array}{c}\text { Radius } \\
(\mathrm{m})\end{array}$ \\
\hline 1 & 0.25 & 0.5 & 0.07 \\
2 & 0.5 & 0.5 & 0.085 \\
3 & 0.5 & 1 & 0.2 \\
4 & 0.75 & 0.5 & 0.12 \\
5 & 0.25 & 1.4 & 0.12 \\
6 & 0.5 & 1.8 & 0.08 \\
7 & 0.75 & 1.5 & 0.13 \\
\hline
\end{tabular}

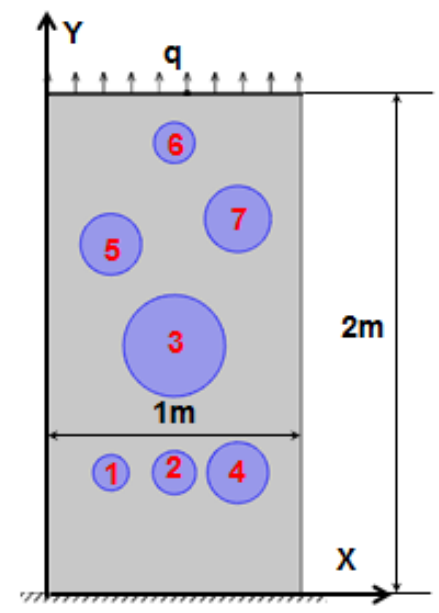

Fig.9. FGM plate with material variation in the $\mathrm{x}$-direction with seven circular inclusions.

We compare the finite element method (FEM) solution to that obtained by XFEM. 


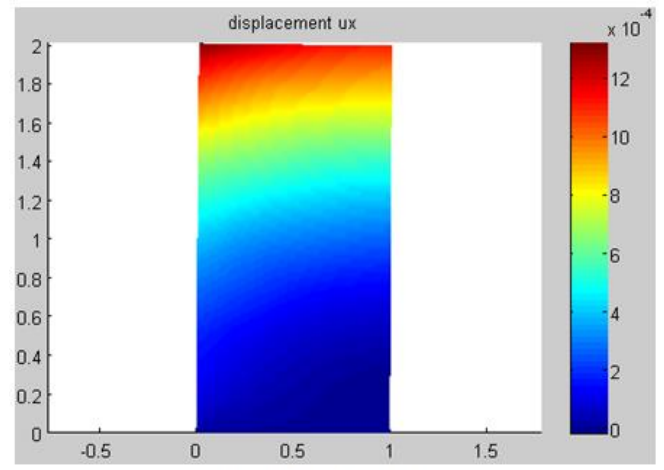

XFEM (Matlab)

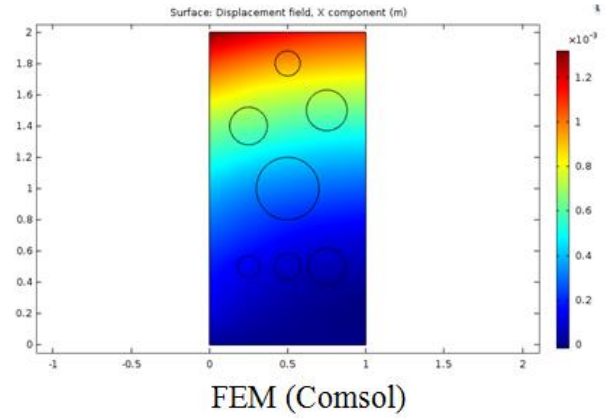

Fig.10. Comparison of displacement results $\mathrm{u}_{\mathrm{x}}$ between XFEM and FEM

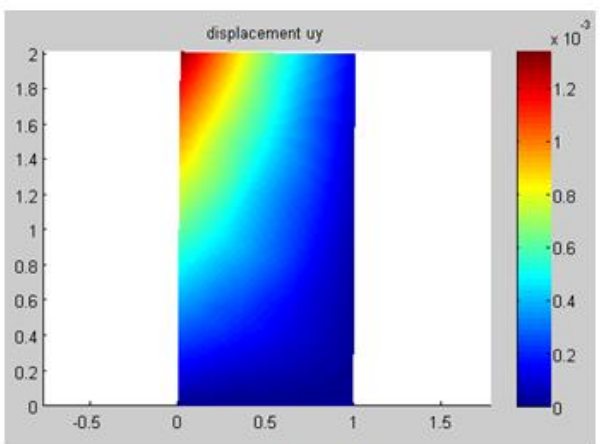

XFEM (Matlab)

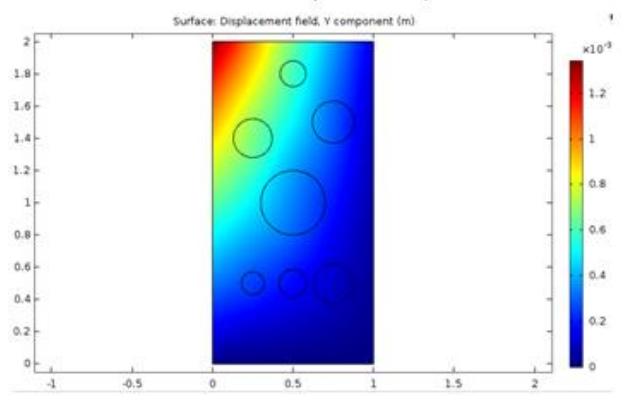

FEM (Comsol)

Fig.11. Comparison of displacement results $\mathrm{u}_{\mathrm{y}}$ between XFEM and FEM

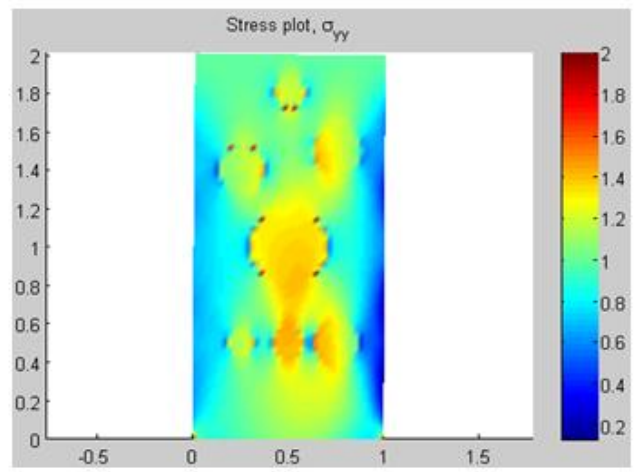

XFEM (Matlab)

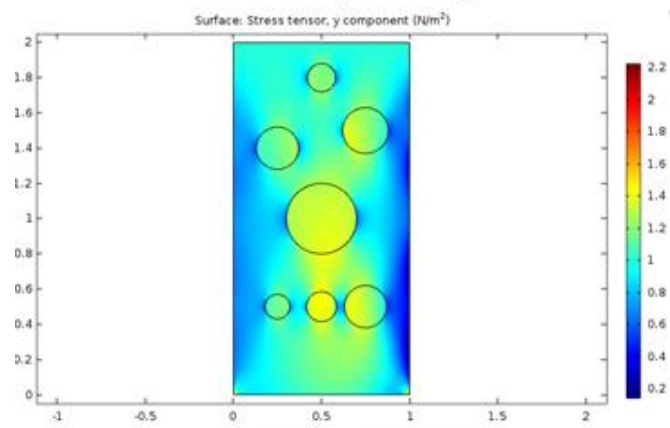

FEM (Comsol)

Fig.12. Comparison of stress results $\sigma_{y y}$ between XFEM and FEM

TABLE 2

COMPARISON OF RESULTS BETWEEN XFEM AND FEM

\begin{tabular}{cccc}
\hline \hline $\begin{array}{c}\text { Displacement } \\
(\mathrm{m})\end{array}$ & XFEM & FEM & \%ERROR \\
\hline Max(uy) & 0.001343 & 0.001344 & $0.07 \%$ \\
$\operatorname{Min}($ uy) & 0 & 0 & $0 \%$ \\
$\operatorname{Max}(\mathrm{ux})$ & 0.001322 & 0.001325 & $0.22 \%$ \\
$\operatorname{Min}(\mathrm{ux})$ & $-1.58 .10^{-5}$ & $-1.59 .10^{-5}$ & $0.62 \%$ \\
\hline
\end{tabular}

The computed results obtained by the XFEM and the FEM are listed in Table 2 including the percentage errors. The minimum and the maximum displacement obtained by the XFEM matches well with those derived from the FEM. The stress and displacement field of the plate are sketched in subsequent Fig. 10-12.

\section{CONCLUSION}

In this paper, an advanced of the XFEM is proposed for modeling multiple random inclusions in functionally graded material. It was observed that XFEM leads to very accurate results when compared with FEM and is suitable for solving discontinous problem when many inclusions with different sizes appear in the body. 
It is convenient to treat those inclusions without meshing the internal boundaries because of the enrichment function. So the inclusion can be easily insert in the model regardless of the mesh generation. The presented approach has shown several advantages and it is promising to be extended to more complicated problems such as modeling the body containning different discontinuity boundaries such as crack, void and inclusion.

\section{REFERENCES}

[1]E. Viola, F. Tornabene, E. Ferretti and N. Fantuzzi, "On Static Analysis of Composite Plane State Structures via GDQFEM and Cell Method", CMES, vol.94, no.5, pp. 421-458, 2013.

[2]J. Zhang, Zh. Qu, Q. Huang, "Elastic fields of a finite plate containing a circular inclusion by the distributed dislocation method", Archive of Applied Mechanics, vol. 86, no. 4, pp 701-712, 2016.

[3]N. Sukumar, D.L. Chopp, N. Moes and T. Belytschko, "Modeling holes and inclusions by level sets in the extended finite-element method", Comput. Methods Appl. Mech. Engrg, vol. 190, pp. 6183-6200, 2001.

[4]Q. Yang, C. Gao and W. Chen, "Stress analysis of a functional graded material plate with a circular hole", Arch Appl Mech, vol. 80, pp. 895-907, 2010.

[5]R. D. List and J. P. O. Silberstein, "Two-dimensional elastic inclusion problems", Mathematical Proceedings of the Cambridge Philosophical Society, vol. 62, no. 2, pp. 303-311, 1966.

[6]X. An, G. Ma, Y. Cai, H. Zhu, "A new way to treat material discontinuities in the numerical manifold method", Comput. Methods Appl. Mech. Engrg, vol. 200, pp. 32963308, 2011.

[7]Y. Krongauz, T. Belytschko, "EFG approximation with discontinuous derivatives", Int. J. Numer. Meth. Engrg, vol. 41, pp. 1215-1233, 1998.

Kim Bang Tran was born in Ho Chi Minh City in Viet Nam. He graduated from Faculty of Applied Science, Engineering Mechanics in Ho Chi Minh City University of Technology, VNUHCM. He got the B.S. and M.S degree in Engineering Mechanics in 2009 and 2012, respectively. His current job is a lecturer in Ho Chi Minh City University of Technology. His research interest consists numerical method, fracture mechanics.
The Huy Tran was born in Binh Phuoc province in Viet Nam. He is the student of Faculty of Applied Science, Engineering Mechanics, Ho Chi Minh City University of Technology, VNU-HCM. His research interest consists finite element method, structural analysis.

Quoc Tinh Bui was born in Quang Nam province in Viet Nam. He graduated from University of Natural Science, VNU-HCM. He got the B.S. degree in Mathematics and Computer Sciences in 2002, European M.S degree in Mechanics of Constructions in 2005 and Ph.D degree in Mechanical Engineering in 2009. Dr. Bui's areas of expertises are computational mechanics with an emphasis on failure and damage mechanics of materials and structures using the finite element models, soft-computing and parallel computing platforms, numerical methods developments including/extended finite elements, (enriched) meshfree methods, isogeometric analysis, phase field modeling, etc. for structural analysis in composite materials.

Tich Thien Truong was born in $\mathrm{Ca}$ Mau province in Viet Nam. He graduated from Faculty of Mechanical Engineering in Ho Chi Minh City University of Technology, VNU-HCM. He got the B.S, M.S degree in Mechanical Engineering in 1986 and 1992, respectively and Ph.D degree in Mechanical Engineering in 2001. His current job is a Vice Dean of Faculty of Applied Science and a lecturer in Ho Chi Minh City University of Technology. His research interest consists numerical method, fracture mechanics, structural analysis. 


\section{Phương pháp phần tử hữu hạn mở rộng trong mô phỏng ứng xử cơ học của tấm vật liệu phân bố chức năng có tạp chất phân bố ngẫu nhiên}

Trần Kim Bằng, Trần Thế Huy, Bùi Quốc Tính, Trương Tích Thiện

Tóm tắt - Vật liệu phân lớp chức năng (functionally graded material - FGM) là loại vật liệu tiên tiến, được ứng dụng nhiều trong các lĩnh vực kỹ thuật hiện đại. Sự xuất hiện của các hạt tạp chất sẽ ảnh hưởng phần nào tới độ bền và ứng xử của vật liệu. Bài báo này mô tả sự ảnh hưởng của các hạt tạp chất nằm lẫn trong tấm phẳng FGM. Biên hình học của vật thể sẽ trở nên phức tạp khi có nhiều tạp chất xuất hiện ngẫu nhiên. Phương pháp phần tử hữu hạn mở rộng được áp dụng để tránh việc phải xây dựng biên hình học khác nhau của những hạt tạp chất. Trong phương pháp số này, sự xấp xỉ phần tử hữu hạn sẽ được thêm vào các hàm làm giàu để mô tả tính chất vật lý của biên bất liên tục vật liệu. Một vài ví dụ mô phỏng số sẽ được đề cập để chứng tỏ ưu thế của phương pháp phần tử hữu hạn mở rộng khi áp dụng vào bài toán bất liên tục vật liệu. Các kết quả tính toán sẽ được so sánh với kết quả của bài báo khoa học uy tín khác và kết quả thu được từ phần mềm COMSOL, phần mềm dựa trên phương pháp phần tử hữu hạn.

Tù khóa- Phương pháp phần tử hữu hạn mở rộng; ngẫu nhiên; tạp chất, vật liệu phân lớp chức năng 